\title{
STAVOVI ODGOJITELJA PREDŠKOLSKE DJECE PREMA GLAZBENIM AKTIVNOSTIMA U VRTIĆU I SAMOPROCJENA KOMPETENTNOSTI ZA NJIHOVU REALIZACIJU
}

\author{
Snježana Dobrota \\ Filozofski fakultet, Sveučilište u Splitu, \\ Hrvatska,dobrota@ffst.hr
}

Primljeno: 19. 6. 2019.

\begin{abstract}
Glazbenim aktivnostima u vrtiću pripada značajna uloga, s obzirom da bavljenje takvim aktivnostima pridonosi razvoju glazbenih sposobnosti, ali i intelektualnom, socijalnom, emocionalnom i tjelesnom razvoju djeteta. U radu su istraženi stavovi odgojitelja predškolske djece prema glazbenim aktivnostima u vrtiću te samoprocjena kompetentnosti za njihovu realizaciju. Rezultati potvrđuju da slušanje glazbe predstavlja značajnu aktivnost slobodnog vremena odgojitelja predškolske djece. Potvrđeno je da odgojitelji kojima se sviđa klasična glazba imaju pozitivnije stavove prema glazbenim aktivnostima u vrtiću. Nije uočena povezanost odlazaka na koncerte klasične glazbe, pohađanja dodatne glazbene poduke, pjevanja u zboru ili klapi te godina radnoga staža sa stavovima prema glazbenim aktivnostima. Rezultati istraživanja ne potvrđuju ni povezanost godina radnoga staža sa samoprocjenom kompetencije za realizaciju glazbenih aktivnosti. I, konačno, većina odgojitelja zadovoljna je opremljenošću vrtića instrumentima za djecu te računalima i projektorima, ali ne i instrumentima za odgojitelje.
\end{abstract}

Ključne riječi: glazbene aktivnosti, kompetentnost, odgojitelj predškolske djece, stavovi, dječji vrtić

\section{Uvod}

Glazbi pripada značajno mjesto u životu svakog djeteta. Bavljenje glazbenim aktivnostima značajno pridonosi cjelovitom razvoju djeteta (Barrett, 2009), a doživljavanje kvalitetnih glazbenih iskustava pozi- 
tivno utječe na kvalitetu njegova sveukupnoga života (Achilles, 1999). Svi susreti djeteta s glazbom ostvaruju se putem igre (Marić i Goran, 2013). Dijete rane i predškolske dobi pjeva pjesme, izvodi glazbene igre i brojalice, sluša glazbu te svira na različitim ritamskim i melodijskim udaraljkama.

Glazbeni razvoj djeteta dio je njegova općeg razvoja pa tako bavljenje glazbenim aktivnostima pozitivno utječe na razvoj glazbenih sposobnosti, ali i na djetetov intelektualni, socijalni, emocionalni i tjelesni razvoj. Rezultati brojnih istraživanja potvrđuju kako bavljenje glazbom poboljšava socijalni, kognitivni i fizički razvoj djeteta (Steele et al., 2013; Rauscher i Hinton, 2011). Mattar (2013) je proveo eksperiment s paralelnim skupinama s djecom u dobi od pet do šest godina. U eksperimentalnoj skupini djeca su osam mjeseci svakodnevno slušala Mozartovu glazbu tijekom dnevnih aktivnosti, dok su djeca u kontrolnoj skupini obavljala dnevne aktivnosti bez glazbene pratnje. Rezultati pokazuju značajnu razliku u socijalnom, kognitivnom i fizičkom razvoju između djece iz eksperimentalne i kontrolne skupine, u korist djece iz eksperimentalne skupine.

Kako ističe Šagud (2006), odgojitelji predškolske djece potiču ili zaustavljaju dječji razvoj primjenom odgovarajućih ili neodgovarajućih pristupa podučavanju. Rezultati istraživanja potvrđuju da stavovi odgojitelja predškolske djece o uključivanju glazbenih aktivnosti u vrtić u prvom redu ovise o njihovoj samoprocjeni glazbenih sposobnosti i kompetencija (Battersby i Cave, 2014; Richards, 1999; Swain i Bodkin-Allen, 2017). Odgojitelji predškolske djece koji imaju kvalitetnije glazbeno obrazovanje pridaju veću važnost glazbenim aktivnostima u vrtiću (Kelly, 1998; Kim i Kemple, 2011), dok su odgojitelji s nedostatnom glazbenom podukom manje zainteresirani za bavljenje glazbenim aktivnostima i ističu poteškoće koje proizlaze iz njihove nedostatne glazbene poduke (Kim, 2013). Koca (2013) smatra da odgojitelji s niskom razinom percipirane efikasnosti u glazbenoj poduci imaju manje povjerenja u svoje sposobnosti približavanja djeteta glazbi.

Što se tiče percepcije odgojitelja predškolske djece o tome koji su ih glazbeni kolegiji i aktivnosti tijekom studija u najvećoj mjeri osposobili za rad s djecom, na prvo mjesto stavljaju aktivnost pjevanja, sviranja ritamskih instrumenata i pokret uz glazbu, dok kolegije iz područja teorije i povijesti glazbe ne smatraju korisnim za rad u vrtiću (Kelly, 1998). Bačlija Sušić (2018) istraživala je glazbene kompetencije stu- 
denata Ranog i predškolskog odgoja s Učiteljskog fakulteta u Zagrebu. Rezultati potvrđuju da sudionici visoko vrednuju svoje temeljne kompetencije i kompetencije vezane uz metodiku i glazbenu kreativnost. Međutim, njihova samoprocjena praktičnih kompetencija i izražena želja za poboljšanjem kompetencija ukazuju na svijest za potrebom daljnjeg usavršavanja i razvoja glazbenih kompetencija. Đurđanović i Stošić (2017) istražile su kakav je interes odgojitelja predškolske djece prema profesionalnom usavršavanju u području glazbe te može li im dodatna glazbena poduka donijeti više zadovoljstva u pripremanju i implementiranju glazbenih aktivnosti u vrtiću. Rezultati ukazuju na to da su odgojitelji predškolske djece zainteresirani za usavršavanje i razvijanje svojih glazbenih sposobnosti i vještina, i to u prvom redu tijekom različitih seminara i drugih oblika cjeloživotnog učenja.

\section{Istraživanje}

\section{Cilj, problemi i hipoteze}

Cilj istraživanja je istražiti stavove odgojitelja predškolske djece prema glazbenim aktivnostima u vrtiću te njihovu samoprocjenu kompetentnosti za realizaciju navedenih aktivnosti. U skladu s formuliranim ciljem postavljeni su sljedeći problemi istraživanja:

1. Ispitati postoji li utjecaj godina radnoga staža na dnevno slušanje glazbe.

2. Ispitati postoji li utjecaj godina radnoga staža, sviđanja klasične glazbe i dodatne glazbene poduke na stavove prema glazbenim aktivnostima.

3. Ispitati postoji li utjecaj godina radnoga staža na samoprocjenu kompetentnosti za realizaciju glazbenih aktivnosti.

4. Ispitati učestalost realizacije pojedinih glazbenih aktivnosti, afinitet odgojitelja predškolske djece prema glazbenim aktivnostima te samoprocjenu kompetentnosti za realizaciju navedenih aktivnosti.

5. Ispitati kako odgojitelji predškolske djece procjenjuju opremljenost vrtića nastavnim sredstvima i pomagalima.

Na temelju definiranog cilja i problema istraživanja postavljene su sljedeće hipoteze: 
H1 Dnevno slušanje glazbe odgojitelja predškolske djece ne razlikuje se s obzirom na godine radnog staža.

H2 Odgojitelji predškolske djece kojima se sviđa klasična glazba imaju pozitivnije stavove prema glazbenim aktivnostima.

H3 Odgojitelji predškolske djece koji odlaze na koncerte klasične glazbe imaju pozitivnije stavove prema glazbenim aktivnostima.

H4 Odgojitelji predškolske djece koji su pohađali glazbenu školu i koji su pjevali/pjevaju u zboru/klapi, imaju pozitivnije stavove prema glazbenim aktivnostima u vrtiću.

H5 Odgojitelji predškolske djece koji imaju više godina radnoga staža imaju pozitivnije stavove prema glazbenim aktivnostima.

H6 Odgojitelji predškolske djece koji imaju više godina radnoga staža procjenjuju se kompetentnijima za realizaciju glazbenih aktivnosti.

H7 Odgojitelji predškolske djece najčešće realiziraju one glazbene aktivnosti prema kojima pokazuju najveći afinitet i za koje se procjenjuju kompetentnijima.

H8 Većina odgojitelja predškolske djece procjenjuje da su vrtići u kojima rade u dovoljnoj mjeri opremljeni instrumentima za djecu, instrumentima za odgajatelje te računalima i projektorima.

\section{Metoda}

\section{Sudionici}

Ispitivanje je provedeno tijekom stručnog skupa 24. Dani ranog $i$ predškolskog odgoja Splitsko-dalmatinske županije, Mirisi djetinjstva u Supetru na otoku Braču na uzorku od 200 odgojitelja predškolske djece iz Splitsko-Dalmatinske, Šibenske, Zadarsko-Kninske, Dubrovačke i Zagrebačke županije $(\mathrm{N}=200)$.

\section{Instrument i postupak ispitivanja}

Za potrebe istraživanja konstruiran je upitnik (Prilog 1) koji sadrži pet dijelova. U prvom dijelu nalaze se pitanja koja se odnose na sociodemografska obilježja sudionika (grad, stručna sprema, godine radnoga staža). Drugi dio pitanja odnosi se na prosječno vrijeme dnevnoga slu- 
šanja glazbe, preferiranje klasične glazbe i posjećivanje koncerata klasične glazbe, pohađanje dodatne glazbene poduke i pjevanje u zboru ili klapi. U trećem dijelu upitnika nalaze se pitanja kojima se ispituje procjena važnosti, stupnja opuštanja, težine, koristi glazbenih aktivnosti te njihove važnosti za cjelokupni razvoj djeteta. Slijede pitanja kojima se procjenjuje kompetentnost odgojitelja predškolske djece za realizaciju glazbenih aktivnosti te procjena opremljenosti vrtića različitim nastavnim sredstvima i pomagalima. Posljednja skupina pitanja odnosi se na procjenu učestalosti realizacije različitih glazbenih aktivnosti, afinitet prema njima i samoprocjena kompetentnosti za njihovu realizaciju.

Sudionicima je objašnjena svrha provođenja istraživanja, zajamčena im je anonimnost te su zamoljeni da iskreno i precizno odgovaraju na pitanja.

\section{Rezultati i diskusija}

H1 Dnevno slušanje glazbe odgojitelja predškolske djece ne razlikuje se s obzirom na godine radnog staža.

Kako bismo testirali prvu hipotezu, proveden je Kruskal-Wallis test, čiji rezultati ukazuju na to da slušanje glazbe predstavlja značajnu aktivnost slobodnog vremena odgojitelja predškolske djece te da se oni ne razlikuju u dnevnom slušanju glazbe s obzirom na godine radnoga staža (Tablica 1). Time je prihvaćena prva hipoteza.

Dobiveni rezultati u skladu su s rezultatima brojnih istraživanja (Lonsdale i North, 2011; Miranda, 2013) koji potvrđuju da je slušanje glazbe jedna od najzastupljenijih aktivnosti slobodnog vremena sudionika, bez obzira na različite sociodemografske varijable.

Tablica 1. Razlike u dnevnom slušanju glazbe s obzirom na godine radnoga staža

\begin{tabular}{|c|c|c|c|}
\hline $\begin{array}{c}\text { Godine radnoga } \\
\text { staža }\end{array}$ & C & H (4,N=200) & p \\
\cline { 1 - 2 } $0-9$ & 3 & & \\
\cline { 1 - 2 } $10-19$ & 3 & \multirow{2}{*}{4.44} & \multirow{2}{*}{.349} \\
\cline { 1 - 2 } $20-29$ & 3 & & \\
\hline $30-39$ & 3 & & \\
\hline $40-49$ & 3 & & \\
\hline
\end{tabular}


H2 Odgojitelji predškolske djece kojima se sviđa klasična glazba imaju pozitivnije stavove prema glazbenim aktivnostima.

Kako bi se provjerila druga hipoteza proveden je Kruskal-Wallis test, pri čemu su stavovi, kao zavisna varijabla, uključivali četiri komponente i to važnost glazbenih aktivnosti u vrtiću, stupanj opuštanja, težinu, korisnost i važnost za razvoj djeteta. Rezultati potvrđuju da se stavovi odgajatelja predškolske djece prema glazbenim aktivnostima značajno razlikuju s obzirom na to sviđa li im se klasična glazba ili ne, pri čemu odgojitelji kojima se sviđa klasična glazba imaju pozitivnije stavove prema glazbenim aktivnostima u vrtiću (Tablica 2). Time je potvrđena postavljena hipoteza.

Dobiveni rezultati u skladu su s rezultatima Dobrote i Barbarić (2017) koji potvrđuju povezanost preferencija klasične glazbe sa stavovima prema nastavi glazbe, te s rezultatima Dobrote (2016) u čijem je istraživanju potvrđen pozitivan utjecaj izloženosti klasičnoj glazbi na stavove prema klasičnoj glazbi i nastavi glazbe.

Tablica 2. Razlike u stavovima prema glazbenima aktivnostima u vrtiću s obzirom na preferiranje klasične glazbe

\begin{tabular}{|l|c|c|c|}
\hline Sviđanje klasične glazbe & C & $\begin{array}{c}\text { H (2, } \\
\text { N=200) }\end{array}$ & p \\
\cline { 1 - 2 } Uopće mi se ne sviđa & 9 & & \\
\cline { 1 - 2 } $\begin{array}{l}\text { Sviđa mi se samo neka kla- } \\
\text { sična glazba }\end{array}$ & 9 & \multirow{2}{*}{10.94} & .004 \\
\cline { 1 - 2 } Sviđa mi se klasična glazba & 9 & & \\
\hline
\end{tabular}

H3 Odgojitelji predškolske djece koji odlaze na koncerte klasične glazbe imaju pozitivnije stavove prema glazbenim aktivnostima.

Kako bi se testirala navedena hipoteza proveden je Mann-Whitney U test, čiji rezultati pokazuju kako odlasci na koncerte klasične glazbe ne utječu na stavove odgojitelja prema glazbenim aktivnostima u vrtiću (Tablica 3), čime je odbačena postavljena hipoteza.

Takvi rezultati nisu u skladu s rezultatima istraživanja koja potvrđuju značajnu ulogu socioekonomskog statusa i učestalosti odlazaka na koncerte klasične glazbe, s jedne, te glazbenih preferencija i stavova prema nastavi glazbe, s druge strane (North i Hargreaves, 2007a; 2007b; 2007c). 
Tablica 3. Razlike u stavovima prema glazbenim aktivnostima u vrtiću s obzirom na odlaske na koncerte klasične glazbe

\begin{tabular}{|c|c|c|c|c|}
\hline $\begin{array}{c}\text { Odlasci na koncerte } \\
\text { klasične glazbe }\end{array}$ & $\mathbf{C}$ & $\mathbf{U}$ & $\mathbf{z}$ & $\mathbf{P}$ \\
\hline $\mathrm{Ne}$ & 9 & 4707.00 & 1.44 & 0.149 \\
\hline $\mathrm{Da}$ & 9 & &
\end{tabular}

H4 Odgojitelji predškolske djece koji su pohađali glazbenu školu i koji su pjevali/pjevaju u zboru/klapi imaju pozitivnije stavove prema glazbenim aktivnostima u vrtiću.

Kako bi se testirala navedena hipoteza ponovno je proveden MannWhitney U test. Rezultati pokazuju kako pohađanje glazbene škole ili pjevanje u zboru/klapi ne utječe na stavove odgajatelja prema glazbenim aktivnostima u vrtiću (Tablica 4). Time je odbačena postavljena hipoteza.

Tablica 4. Razlike u stavovima prema glazbenim aktivnostima u vrtiću s obzirom na pohađanje dodatne glazbene škole i pjevanje u zboru/klapi

\begin{tabular}{|l|c|c|c|c|}
\hline $\begin{array}{l}\text { Pohađanje glazbe škole i } \\
\text { pjevanje u zboru/klapi }\end{array}$ & $\mathbf{C}$ & $\mathbf{U}$ & $\mathbf{z}$ & $\mathbf{p}$ \\
\cline { 1 - 2 } $\mathrm{Ne}$ & 9 & \multirow{2}{*}{3489.00} & 1.03 & 0.305 \\
\hline
\end{tabular}

H5 Odgojitelji predškolske djece koji imaju više godina radnoga staža imaju pozitivnije stavove prema glazbenim aktivnostima.

Kako bismo izračunali razlikuju li se stavovi odgajatelja prema glazbenim aktivnostima u vrtiću s obzirom na godine njihova radnoga staža, proveden je Kruskal-Wallis test. Rezultati ukazuju na to da se odgajatelji ne razlikuju u stavovima prema glazbenim aktivnostima u vrtiću s obzirom na godine radnoga staža (Tablica 5). Time je odbačena postavljena hipoteza. 
Tablica 5. Razlike u stavovima prema glazbenim aktivnostima u vrtiću s obzirom na godine radnoga staža

\begin{tabular}{|c|c|c|c|}
\hline Godine radnoga staža & $\mathbf{C}$ & $\begin{array}{c}\mathrm{H}(4, \\
\mathrm{N}=200)\end{array}$ & p \\
\hline $0-9$ & 9 & \multirow{5}{*}{9.02} & \multirow{5}{*}{.060} \\
\hline $10-19$ & 9 & & \\
\hline $20-29$ & 9 & & \\
\hline $30-39$ & 9 & & \\
\hline $40-49$ & 9 & & \\
\hline
\end{tabular}

H6 Odgojitelji predškolske djece koji imaju više godina radnoga staža procjenjuju se kompetentnijima za realizaciju glazbenih aktivnosti.

Kako bi se provjerila navedena hipoteza proveden je Kruskal-Wallis test, pri čemu je procjena kompetentnosti za realizaciju glazbenih aktivnosti uključivala tri komponentne: samoprocjenu kompetentnosti za realizaciju glazbenih aktivnosti, procjenu korisnosti pohađanja dodatne glazbene poduke i procjenu korisnosti dolaska glazbenoga stručnjaka u skupinu jedan put tjedno. Rezultati potvrđuju kako se odgojitelji ne razlikuju u procjeni kompetentnosti za realizaciju glazbenih aktivnosti s obzirom na godine radnoga staža, čime je odbačena postavljena hipoteza.

Rezultati istraživanja Stolić (2015) pokazuju da stručna sprema odgojitelja predškolske djece ne utječe na potrebu podrške u realizaciji glazbenih aktivnosti, jer svi sudionici, bez obzira na razinu stručne spreme, iskazuju jasnu potrebu pomoći glazbenoga stručnjaka i to najviše u sviranju klavira ili gitare. 
Tablica 6. Razlike u procjeni kompetentnosti za realizaciju glazbenih aktivnosti s obzirom na godine radnoga staža

\begin{tabular}{|c|c|c|c|}
\hline $\begin{array}{c}\text { Godine radnoga } \\
\text { staža }\end{array}$ & $\mathbf{C}$ & $\begin{array}{c}\text { H (4, } \\
\mathbf{N = 2 0 0})\end{array}$ & $\mathbf{p}$ \\
\hline $0-9$ & 6 & \multirow{2}{*}{3.22} & \\
\cline { 1 - 2 } $10-19$ & 6 & \multirow{2}{*}{0.521} \\
\cline { 1 - 2 } $20-29$ & 6 & & \\
\cline { 1 - 2 } $30-39$ & 6 & & \\
\hline $40-49$ & 5.5 & & \\
\hline
\end{tabular}

H7 Odgojitelji predškolske djece najčešće realiziraju one glazbene aktivnosti prema kojima pokazuju najveći afinitet i za koje se procjenjuju kompetentnijima.

Kako bismo testirali postavljenu hipotezu, izračunali smo srednje vrijednosti za učestalost realizacije glazbenih aktivnosti, afinitet prema glazbenim aktivnostima te odgojiteljevu samoprocjenu kompetentnosti za realizaciju svake od navedenih glazbenih aktivnosti (Tablica 7).

Odgojitelji najčešće realiziraju sviranje, slijedi slušanje glazbe, brojalice te pjevanje/glazbene igre. Što se tiče afiniteta prema glazbenim aktivnostima, najveći afinitet pokazuju prema sviranju, zatim prema brojalicama, slušanju glazbe i pjevanju/glazbenim igrama. Odgojitelji se procjenjuju najkompetentnijima za realizaciju sviranja, zatim slušanja glazbe, obradu brojalica i pjevanja/glazbenih igara. Time je potvrđena postavljena hipoteza.

Dobiveni rezultati nisu u skladu s rezultatima istraživanja Stolić (2015) koja uočava da odgojitelji najčešće realiziraju pjevanje, slijede glazbene igre, slušanje glazbe, izvođenje brojalica i sviranje. Analizirajući aktivnosti koje najviše utječu na razvoj glazbenih sposobnosti, odgojitelji na prvo mjesto stavljaju pjevanje, nakon toga slušanje glazbe, izvođenje brojalica, glazbene igre i sviranje. 
Tablica 7. Učestalost realizacije glazbenih aktivnosti, afinitet prema glazbenim aktivnostima i samoprocjena kompetentnosti za realizaciju glazbenih aktivnosti

\begin{tabular}{|c|c|c|c|c|c|c|c|c|c|}
\hline \multirow{2}{*}{$\begin{array}{l}\text { Glazbena } \\
\text { aktivnost }\end{array}$} & \multirow[t]{2}{*}{$\mathbf{N}$} & \multirow[t]{2}{*}{ Min. } & \multirow[t]{2}{*}{ Max. } & \multicolumn{2}{|c|}{$\begin{array}{l}\text { Učestalost } \\
\text { realizacije }\end{array}$} & \multicolumn{2}{|c|}{ Afinitet } & \multicolumn{2}{|c|}{$\begin{array}{l}\text { Samoprocjena } \\
\text { kompetentnosti }\end{array}$} \\
\hline & & & & M & SD & M & SD & M & SD \\
\hline $\begin{array}{l}\text { Izvođenje } \\
\text { brojalica }\end{array}$ & \multirow{4}{*}{200} & \multirow{4}{*}{1} & \multirow{4}{*}{4} & 2,11 & 0,93 & 2,55 & 0,99 & 2,15 & 0,93 \\
\hline $\begin{array}{l}\text { Pjevanje i } \\
\text { glazbene igre }\end{array}$ & & & & 1,82 & 0,76 & 1,62 & 0,75 & 1,84 & 0,84 \\
\hline Sviranje & & & & 3,67 & 0,72 & 3,53 & 0,81 & 3,56 & 0,87 \\
\hline $\begin{array}{l}\text { Slušanje } \\
\text { glazbe }\end{array}$ & & & & 2,41 & 1,02 & 2,31 & 0,97 & 2,46 & 0,99 \\
\hline
\end{tabular}

H8 Većina odgojitelja predškolske djece procjenjuje da su vrtići u kojima rade u dovoljnoj mjeri opremljeni instrumentima za djecu, instrumentima za odgajatelje te računalima i projektorima.

Kako bi se provjerila postavljena hipoteza analizirani su odgovori odgajatelja na pitanje o dostatnosti opremljenosti vrtića instrumentima za djecu, instrumentima za odgajatelje te računalima i projektorima (Tablica 8). Što se tiče opremljenosti vrtića instrumentima za djecu te računalima i projektorima, otprilike polovina odgajatelja zadovoljna je opremljenošću vrtića navedenim sredstvima i pomagalima. Međutim, što se tiče instrumenata za odgajatelje, samo je jedna trećina odgajatelja zadovoljna opremljenošću vrtića. Time je djelomično potvrđena postavljena hipoteza.

Do sličnih je rezultata došla i Stolić (2015) koja navodi da $60 \%$ odgojitelja u svojim vrtićima posjeduje neki od instrumenata (klavir, gitaru i sl.).

Tablica 8. Procjena opremljenosti vrtića nastavnim pomagalima i sredstvima

\begin{tabular}{|c|c|c|c|}
\hline $\begin{array}{c}\text { Dostatna } \\
\text { opremljenost }\end{array}$ & $\begin{array}{c}\text { Instrumenti } \\
\text { za djecu }\end{array}$ & $\begin{array}{c}\text { Instrumenti } \\
\text { za odgojitelje }\end{array}$ & $\begin{array}{c}\text { Računala } \\
\text { i projektori }\end{array}$ \\
\hline $\mathrm{Ne}$ & $50.50 \%$ & $67 \%$ & $54 \%$ \\
\hline $\mathrm{Da}$ & $49.50 \%$ & $33 \%$ & $46 \%$ \\
\hline
\end{tabular}




\section{Zaključak}

Rezultatima istraživanja potvrđeno je kako slušanje glazbe predstavlja značajnu aktivnost slobodnog vremena odgojitelja predškolske djece. Nadalje, potvrđeno je da odgojitelji kojima se sviđa klasična glazba imaju pozitivnije stavove prema glazbenim aktivnostima u vrtiću. Nije uočena povezanost odlazaka na koncerte klasične glazbe, pohađanja dodatne glazbene poduke, pjevanja u zboru ili klapi te godina radnoga staža sa stavovima prema glazbenim aktivnostima. Nije uočena ni povezanost godina radnoga staža sa samoprocjenom kompetencije za realizaciju glazbenih aktivnosti. Odgojitelji predškolske djece najčešće realiziraju one glazbene aktivnosti prema kojima pokazuju najveći afinitet i za koje se procjenjuju kompetentnijima. I, konačno, većina odgojitelja predškolske djece zadovoljna je opremljenošću vrtića instrumentima za djecu te računalima i projektorima, ali ne i instrumentima za odgojitelje.

Bavljenje glazbenim aktivnostima u vrtiću pridonosi razvoju glazbenih sposobnosti djeteta, ali i njegovom socijalnom, emocionalnom, intelektualnom i fizičkom razvoju. Djeca uživaju tijekom susreta s glazbom, bez obzira radi li se o pjevanju, sviranju, izvođenju glazbenih igara i brojalica ili slušanju glazbe uz pokret. Ono što glazbenim pedagozima i odgojiteljima predškolske djece ide u prilog jest činjenica da su djeca ove dobi otvorena i tolerantna prema različitim vrstama glazbe (Hargreaves, 1982). Pri odabiru glazbe za rad s djecom potrebno je voditi računa o tome da se radi o reprezentativnoj, kvalitetnoj i djeci primjerenoj glazbi.

»Samo umjetnički vrijedna muzika može djelovati na dijete, pobuditi u njemu plemenite osjećaje, formirati njegov ukus i razviti u njemu trajniju ljubav prema muzici. Taj zahtjev je izražen riječima: 'Za djecu je dobro samo ono što je savršeno'.« (Manasteriotti, 1982, 128) 


\section{Literatura}

Achilles, Elayne (1999), »Creating musical environments in early childhood programs «, Young Children, 54(1), str. 21-26.

Bačlija Sušić, Blaženka (2018), »Preschool teachers' music competences based on preschool education students' self-assessment «, Croatian Journal of Education, 20(1), str. 113-129. doi: https://doi.org/10.15516/cje.v20i0.3048

Barrett, Margaret S. (2009), »Sounding lives in and through music: A narrative inquiry of the 'everyday' musical engagement of a young child «, Journal of Early Childhood Research, 7, str. 115-134.

doi: https://doi.org/10.1177/1476718X09102645

Battersby, Sharyn L.; Cave, Agnes (2014), »Preservice classroom teachers' preconceived attitudes, confidence, beliefs, and self-efficacy toward integrating music in the elementary curriculum «, Update Applications of Research in Music Education, 32(2), str. 52-59.

doi: https://doi.org/10.1177/8755123314521033

Dobrota, Snježana (2016), »Stavovi studenata prema umjetničkoj glazbi i glazbenoj nastavi«, Školski vjesnik. Časopis za pedagogijsku teoriju i praksu, 65, str. 33-47.

Dobrota, Snježana; Barbarić, Sara (2017), »Croatian elementary school students' attitudes towards music lessons «, The Journal of Music Education of the Academy of Music in Ljubljana, 26, str. 5-19.

Đuđanović, Miomira; Stošić, Irena (2017), »Preschool teachers and their levels of interest in developing musical competencies«, Facta Universitatis. Series: Visual Arts and Music, 3(1), str. 15-27.

doi: https://doi.org/10.22190/FUVAM1701015D

Hargreaves, David J. (1982), »The development of aesthetic reactions to music «, Psychology of Music. Special Issue, str. 51-54.

Kelly, Steven N. (1998), »Preschool classroom teachers' perception of useful music skills and understandings «, Journal of Research in Music Education, 46(3), str. 374-383. doi: https://doi.org/10.2307/3345549

Kim, Hae Kyoung (2013), »A comparison of early childhood preservice teacher's beliefs about music and developmentally appropriate practice between South Korea and the U. S.«, Australasian Journal of Early Childhood, 38(2), str. 122-128. doi: https://doi.org/10.1177/183693911303800215

Kim, Hae Kyoung; Kemple, Kristen M. (2011), »Is music an active developmental tool or simply a supplement? Early childhood preservice teachers' beliefs about music «, Journal of Early Childhool Teacher Education, 32(2), str. 135147. doi: https://doi.org/10.1080/10901027.2011.572228 
Koca, Sehriban (2013), »An investigation of music teaching self-efficacy levels of prospective preschool teachers«, Educational Research and Review, 8(12), str. 897-900.

Lonsdale, Adam J.; North, Adrian C. (2011), »Why do we listen to music? A uses and gratifications analysis «, British Journal of Psychology, 102(1), str. 108134. doi: https://doi.org/10.1348/000712610X506831

Manasteriotti, Višnja (1982), Muzički odgoj na početnom stupnju, Zagreb: Školska knjiga.

Marić, Ljerka; Goran, Ljiljana (2013), Zapjevajmo radosno. Metodički priručnik za odgojitelje, studente i roditelje, Zagreb: Golden Marketing - Tehnička knjiga.

Mattar, Jehan Wadie (2013), »The effect of Mozart's music on child development in a Jordanian kindergarten«, Education, 133(3), str. 370-377.

Miranda, Dave (2013), »The role of music in adolescent development: much more than the same old song «, International Journal of Adolescence and Youth, 18(1), str. 5-22, doi: https://doi.org/10.1080/02673843.2011.650182

North, Adrian C.; Hargreaves, David J. (2007a), »Lifestyle correlates of musical preference: 1. Relationships, living arrangements, beliefs, and crime «, Psychology of Music, 35(1), str. 58-87.

doi: https://doi.org/10.1177/0305735607068888

North, Adrian C.; Hargreaves, David J. (2007b), »Lifestyle correlates of musical preference: 2. Media, leisure time and music«, Psychology of Music, 35(2), str. 179-200. doi: https://doi.org/10.1177/0305735607070302

North, Adrian C.; Hargreaves, David J. (2007c), »Lifestyle correlates of musical preference: 3. Travel, money, education, employment and health «, Psychology of Music, 35(3), str. 473-497.

doi: https://doi.org/10.1177/0305735607072656

Rauscher, Frances H.; Hinton, Sean C. (2011), »Music instruction and its diverse extra-musical benefits «, Music Perception, 29(2), str. 215-226.

doi: https://doi.org/10.1525/mp.2011.29.2.215

Richards, Carol (1999), »Early childhood preservice teachers' confidence in singing «, Journal of Music Teacher Education, 9(1), str. 6-17.

doi: https://doi.org/10.1177/105708379900900103

Steele, Christopher J.; Bailey, Jennifer A.; Zatorre, Robert J.; Penhune, Virginia B. (2013), »Early musical training and white-matter plasticity in the Corpus Callosum: Evidence for a sensitive period «, The Journal of Neuroscience, 33(3), str. 1282-1290. doi: https://doi.org/10.1523/JNEUROSCI.3578-12.2013

Stolić, Jasmina (2015), »Razvijanje muzičkih sposobnosti predškolske dece kroz određene oblike muzičkih aktivnosti«, Istraživanja u pedagogiji, 5(2), str. 31-44. doi: https://doi.org/10.17810/2015.14 
Swain, Nicola; Bodkin-Allen, Sally (2017), »Developing singing confidence in early childhood teachers using acceptance and commitment therapy and group singing: A randomized trial «, Research Studies in Music Education, 39(1), str. 1-12. doi: https://doi.org/10.1177/1321103X17700141

Šagud, Mirjana (2006), Odgajatelj kao refleksivni praktičar, Petrinja: Visoka učiteljska škola u Petrinji.

\section{THE OPINIONS OF PRE-SCHOOL EDUCATORS TOWARDS KINDERGARTEN MUSIC ACTIVITIES AND A SELF-ASSESSMENT OF THEIR COMPETENCIES TO PERFORM THEM}

\section{Snježana Dobrota}

Musical activities in kindergarten play an important role, especially since engaging in such activities contributes to the development of musical capabilities and intellectual, social, emotional, and physical child development. This research examines the opinions of kindergarten teachers towards musical activities, as well as a self-assessment of their competencies to perform them. The results affirm that listening to music is a significant free time activity for kindergarten teachers. It has also been affirmed that teachers who enjoy classical music have more positive opinions towards musical activities in kindergarten. No connection was noted between opinions towards musical activities and attending classical concerts, additional musical education, singing in choirs or traditional a cappella groups, or years of work experience. The results of this research also did not affirm a connection between years of work experience and self-assessments of competencies to perform musical activities. Finally, the majority of teachers were satisfied with their schools'stock of children's instruments, computers, and projectors, but not with instruments for teachers.

Key words: musical activities, competency, kindergarten teacher, opinions, kindergarten 


\section{PRILOG 1.}

Poštovani!

Pred Vama se nalazi kratki upitnik koji će nam pomoći u istraživanju Vaših stavova prema glazbenim aktivnostima u dječjem vrtiću. Upitnik je anoniman, zanimaju nas prosječni rezultati, stoga Vas molimo da iskreno odgovorite na postavljena pitanja. Unaprijed zahvaljujemo na suradnji!

1. Grad/mjesto u kojemu se nalazi dječji vrtić u kojemu radite:

2. Vaša stručna sprema:

a) srednja stručna sprema

b) viša stručna sprema

c) visoka stručna sprema

3. Godine radnoga staža:
a) $0-10$
b) $10-20$
c) $20-30$
d) $30-40$
e) više od 40

4. Koliko vremena dnevno u prosjeku slušate glazbu (zaokružite samo jedan odgovor)?
a) uopće je ne slušam
b) slušam je jedan do dva sata dnevno
c) slušam je više sati dnevno
d) slušam je cijeli dan

5. Sviđa li Vam se klasična (umjetnička) glazba (Vivaldi, Bach, Beethoven, Mozart...)? (zaokružite samo jedan odgovor)

a) uopće mi se ne sviđa

b) sviđa mi se samo neka klasična (umjetnička) glazba

c) sviđa mi se 
6. Odlazite li na koncerte umjetničke glazbe, opere i balete? a) ne b) da

7. Jeste li pohađali glazbenu školu ili dodatnu glazbenu poduku? a) ne b) da

8. Jeste li pjevali ili još uvijek pjevate u zboru ili klapi? a) ne b) da

9. Prema Vašem mišljenju, glazbenim aktivnostima u vrtiću pripada:

a) nevažno mjesto

b) važno mjesto

10. Prema Vašem mišljenju, glazbene aktivnosti u vrtiću su:

a) aktivnosti koje opuštaju dijete

b) aktivnosti koje opterećuju dijete

11. Prema Vašem mišljenju, glazbene aktivnosti u vrtiću su:

a) teške za djecu

b) lagane za djecu

12. Prema Vašem mišljenju, glazbene aktivnosti u vrtiću su:

a) beskorisne za dijete

b) korisne za dijete

13. Prema Vašem mišljenju, glazbene aktivnosti u vrtiću važne su za:

a) glazbeni razvoj djeteta

b) cjelokupni razvoj djeteta (intelektualni, emocionalni, tjelesni, socijalni, glazbeni)

14. Smatrate li se kompetentnima za kvalitetnu realizaciju glazbenih aktivnosti? a) ne b) da

15. Procjenjujete li korisnim pohađati dodatnu edukaciju iz područja glazbe (seminari, radionice i sl.)? a) ne b) da

16. Smatrate li da bi bilo korisno da u Vašu skupinu jedan put tjedno dolazi glazbeni stručnjak koji bi, zajedno s Vama, realizirao glazbene aktivnosti? a) ne b) da

17. Smatrate li da je vrtić u kojemu radite u dovoljnoj mjeri opremljen instrumentima za djecu (različite udaraljke i sl.)? a) ne b) da 
18. Smatrate li da je vrtić u kojemu radite u dovoljnoj mjeri opremljen instrumentima za odgajatelje (sintisajzer, klavir i sl.)? a) ne b) da

19. Smatrate li da je vrtić u kojemu radite u dovoljnoj mjeri opremljen različitim nastavnim sredstvima (računalo, laptop, projektor i sl.)? a) ne b) da

20. Poredajte po redu glazbene aktivnosti prema tome koliko ih često realizirate u svome radu. Aktivnost koju najčešće realizirate stavite na prvo mjesto (pored nje upišite broj 1), drugu po redu aktivnost stavite na drugo mjesto (pored njega upišite broj 2) i tako sve do broja četiri (na 4. mjestu će biti aktivnost koju najrjeđe realizirate s djecom).

\begin{tabular}{|l|l|}
\hline Glazbena aktivnost & Ocjena \\
\hline Brojalice & \\
\hline $\begin{array}{l}\text { Pjevanje pjesama i izvođenje } \\
\text { glazbenih igara }\end{array}$ & \\
\hline Sviranje & \\
\hline Slušanje glazbe & \\
\hline
\end{tabular}

21. Poredajte po redu glazbene aktivnosti prema tome koliko pokazujete afiniteta prema njima. Aktivnost koju najviše volite stavite na prvo mjesto (pored nje upišite broj 1), drugu po redu aktivnost stavite na drugo mjesto (pored njega upišite broj 2) i tako sve do broja četiri (na 4. mjestu će biti aktivnost prema kojoj pokazujete najmanje afiniteta).

\begin{tabular}{|l|l|}
\hline \multicolumn{1}{|c|}{ Glazbena aktivnost } & Ocjena \\
\hline Brojalice & \\
\hline $\begin{array}{l}\text { Pjevanje pjesama i izvođenje } \\
\text { glazbenih igara }\end{array}$ & \\
\hline Sviranje & \\
\hline Slušanje glazbe & \\
\hline
\end{tabular}


22. Poredajte po redu glazbene aktivnosti prema tome koliko procjenjujete da ste kompetentni za njihovu realizaciju. Aktivnost za koju ste smatrate da imate najveće kompetencije stavite na prvo mjesto (pored nje upišite broj 1), drugu po redu aktivnost stavite na drugo mjesto (pored njega upišite broj 2) i tako sve do broja četiri (na 4. mjestu će biti aktivnost prema kojoj smatrate da imate najmanje kompetencije).

\begin{tabular}{|l|l|}
\hline \multicolumn{1}{|c|}{ Glazbena aktivnost } & Ocjena \\
\hline Brojalice & \\
\hline Pjevanje pjesama i izvođenje glazbenih igara & \\
\hline Sviranje & \\
\hline Slušanje glazbe & \\
\hline
\end{tabular}

